\title{
Multiplex PCR for identifying mycobacterial isolates
}

\author{
M Cormican, M Glennon, U Ni Riain, J Flynn
}

\begin{abstract}
Aims-To develop a multiplex polymerase chain reaction (PCR) method to facilitate identification of mycobacterial isolates. Methods-Type strains of 14 species of mycobacteria and 56 clinical isolates were lysed by boiling in TE Triton. The lysate $(5 \mu \mathrm{l})$ was used directly in a PCR reaction incorporating three pairs of PCR primers expected to amplify fragments from the genome of (a) all mycobacteria, (b) Mycobacterium tuberculosis complex only and (c) $M$ avium only. PCR products were visualised by electrophoresis on agarose gels.

Results-Multiplex PCR applied to 14 type strains yielded patterns on electrophoresis which permitted identification of the mycobacterial isolates as $M$ tuberculosis complex, $M$ avium or as mycobacteria other than the former. The identification of 56 clinical isolates by multiplex PCR was consistent with other methods and was accomplished in less than one working day. Conclusions-This method may facilitate rapid and convenient identification of most clinical isolates of mycobacteria by PCR and gel electrophoresis. Further evaluation is warranted.

(f Clin Pathol 1995;48:203-205)
\end{abstract}

Keywords: PCR, mycobacteria, identification.

The number of mycobacterial species known to cause human disease has increased considerably in recent years ${ }^{1}$ and considerable progress has been made in improving the speed of detection of mycobacteria using both culture ${ }^{2}$ and non-culture techniques. ${ }^{34}$ However, the processes involved in the identification of cultured mycobacteria could be improved. Rapid identification of Mycobacterium tuberculosis and

Department of Medical Microbiology,

University College

Hospital, Galway,

Ireland

M Cormican

U Ni Riain

J Flynn

National Diagnostics Centre, University

College, Galway,

Ireland

M Glennon

Correspondence to: Dr M Cormican.

Accepted for publication 25 August 1994 $M$ avium can be accomplished using commercially available DNA probes. ${ }^{5}$ At present probes are not readily available for the less common species of mycobacteria and the need to examine cultures with an extensive array of probes may prove to be expensive.

A number of general methods for the identification of mycobacteria based on interspecies genetic differences have been described. Telenti et $a l^{6}$ described a method based on interspecies variations in the sequence of the gene encoding the 65 kilodalton mycobacterial heat shock protein. Polymerase chain reaction (PCR) primers were designed to amplify a 439 base pair fragment of the gene. The sequence variation in the fragment from each species was revealed by digestion of separate aliquots of the amplified fragment by two restriction endonucleases, BstE11 and Hae111. Similar methods have been described based on other areas of the mycobacterial genome by Vaneechoute $e t a l^{7}$ and by Plikaytis et al. ${ }^{8}$

We have previously performed an evaluation of the method of Telenti et al and found it useful. ${ }^{9}$ The method could be made more suitable for use in the clinical laboratory if the need to perform digestion on the PCR fragment from most isolates could be eliminated.

We and others have previously studied a primer pair MPB64-1 and MPB64-2 which amplify a 240 base pair product exclusively from members of the $M$ tuberculosis complex ( $M$ tuberculosis, $M$ bovis, $M$ bovis $B C G) .{ }^{1011}$ On review of the literature, we identified a primer pair which amplified a 180 base pair fragment exclusively from $M$ avium. ${ }^{12}$ A multiplex PCR reaction incorporating all three primer pairs might permit identification of members of the $M$ tuberculosis complex and $M$ avium without the need for restriction enzyme digestion. Gel electrophoresis of the PCR products from a reaction including all three primer pairs was expected to yield two bands from $M$ tuberculosis complex isolates (one at 439 base pairs and one at 240 base pairs), two bands from $M$ avium isolates (one at 439 base pairs and one at 180 base pairs) and a single band from all other mycobacterial species. Those clinical isolates which are neither $M$ tuberculosis complex nor $M$ avium could then be identified by restriction endonuclease digestion as described previously. ${ }^{69}$

\section{Methods}

CULTURE

The following type strains were obtained from the Central Public Health Laboratory, London. $M$ tuberculosis $\mathrm{H} 37 \mathrm{Rv}$ NCTC07416, $M$ bovis NCTC10772, $M$ avium NCTC8559, $M$ intracellulare NCTC10425, $M$ scrofulaceum NCTC10803, $M$ fortuitum NCTC2006, $M$ chelonae NCTC, $M$ xenopi NCTC10042, $M$ gordonae NCTC10267, M terrae NCTC10856, and $M$ szulgai NCTC10831. M kansasii, $M$ marinum, $M$ asiaticum, $M$ non-chromogenicum, $M$ phlei, and $M$ simiae were locally maintained derivatives of type cultures. Of the clinical isolates, 36 were from our laboratory and 20 from the Mycobacterium Reference Unit, Public Health Laboratory Service, Cardiff. 
PREPARATION OF MYCOBACTERIA FOR AMPLIFICATION

Mycobacteria were cultured in Bactec medium or on Lowenstein-Jensen slopes. The mycobacteria were harvested from $0.5 \mathrm{ml}$ liquid culture by centrifugation and from Lowenstein-Jensen slopes with a sterile loop. The cells were suspended in $50 \mu \mathrm{TE}$ Triton (10 mmol Tris/ $\mathrm{HCl}, \mathrm{pH} 8.0,1 \mathrm{mmol}$ EDTA, and $1 \%$ Triton $X 100$ ) and boiled for $30 \mathrm{~min}-$ utes to induce cell lysis. This lysate $(5 \mu \mathrm{l})$ was used as the template in the PCR reactions.

\section{DNA AMPLIFICATION}

Oligonucleotides Tb11 (5'-ACCAACGATGGTGTGTCCAT-3') and Tb12 (5'-CTTGTCGAACCGCATACCCT-3'), ${ }^{6} \mathrm{MPB} 64-1$ (5'TCCGCTGCCAGTCGGCTTCC-3') and MPB64-2 (5'-GTCCTCGCGAGTCTAGGCCA-3'), ${ }^{111}$ and MYCGEN-F (5'-AGAGTTTGATCCTGGCTCAG-3') and MYCAV-R (5'-ACCAGAAGACATGCGTCTTG-3' $)^{12}$ were synthesised by Pharmacia (Sollentuna, Sweden). PCR was performed in $25 \mu \mathrm{l}$ reaction volumes covered with two drops of mineral oil. The conditions were $100 \mathrm{mM} \mathrm{KCl}, 20 \mathrm{mM}$ Tris/ $\mathrm{HCl}$ (pH 8.0), $1.5 \mathrm{mM} \mathrm{MgCl}, 0.2 \%$ Tri-

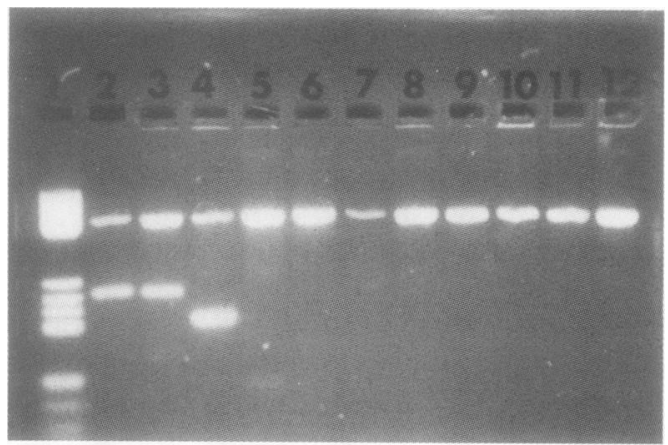

Figure 1 An ethidium bromide stained 3.5\% Nu-Sieve agarose gel showing patterns obtained on electrophoresis of multiplex PCR products. Lane 1, molecular weight marker $V$ (Boehringer Mannheim, Mannheim, Germany); lane 2, $M$ tuberculosis; lane 3, $M$ bovis; lane 4, $M$ avium; lane 5, $M$ intracellulare; lane 6, M scrofulaceum; lane 7 , $M$ kansasii; lane 8, M xenopi; lane 9, $M$ szulgai; lane $10, M$ chelonae; lane $11, M$ fortuitum; lane $12, M$ marinum.

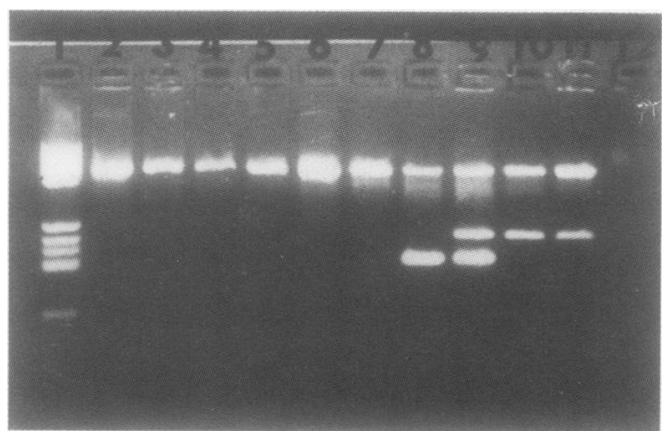

Figure 2 An ethidium bromide stained 3.5\% Nu-Sieve agarose gel showing patterns obtained on electrophoresis of multiplex PCR products. Lane 1, molecular weight marker $V$ (Boehringer Mannheim); lane 2, M asiaticum; lane 3, $M$ gordonae; lane 4, $M$ terrae; lane 5, $M$ nonchromogenicum; lane $6, M$ phlei; lane $7, M$ simiae; lane 8 , mixed culture of $M$ avium and $M$ terrae; lane 9, mixed culture of $M$ avium and $M$ tuberculosis; lanes 10 and 11, clinical isolates of $M$ tuberculosis. ton $\mathrm{X} 100,200 \mu \mathrm{M}$ each of deoxynucleotide triphosphate (dATP, dUTP, dGTP, and dCTP), $0.5 \mu \mathrm{M}$ each of TB11 and TB12, $0.15 \mu \mathrm{M}$ each of MPB64-1 and MPB64-2, $0.45 \mu \mathrm{M}$ each of MYCGEN-F and MYCAV$R$, and 0.63 units of Taq polymerase (Promega, Madison, Wisconsin, USA). The thermal profile used was $95^{\circ} \mathrm{C}$ for one minute, $60^{\circ} \mathrm{C}$ for one minute and $72^{\circ} \mathrm{C}$ for one minute; $45 \mathrm{am}$ plification cycles were performed. PCR products were analysed by electrophoresis of a $5 \mu \mathrm{l}$ aliquot of the reaction on an ethidium bromide stained agarose gel. Where appropriate equal aliquots of the remaining reaction volume were digested as previously described. ${ }^{69}$ Standard precautions against contamination, including physical separation and use of plugged pipette tips and positive displacement tips, were taken and negative controls were included with each PCR run.

\section{Results}

The multiplex PCR method applied to $M$ tuberculosis and $M$ bovis yielded the expected species specific 240 base pair band and the mycobacterial genus specific band at 439 base pairs (fig 1). Amplification of $M$ avium yielded a band at 180 base pairs in addition to the 439 base pair band (fig 1). The $M$ avium specific band at 180 base pairs was also detected from mixed cultures of $M$ avium and $M$ terrae (fig 2). A mixed culture of $M$ avium and $M$ tuberculosis yielded both species specific bands in addition to the common band at 439 base pairs (fig 2). The other 11 mycobacterial species including $M$ intracellulare yielded only the genus specific band at 439 base pairs.

The series of 56 clinical isolates analysed were grouped on the basis of the multiplex PCR reaction as $M$ avium (28 strains), $M$ tuberculosis complex (17 strains) and other mycobacteria (11 strains). The other mycobacteria were identified as $M$ intracellulare $(\mathrm{n}=$ 2), $M$ kansasii $(\mathrm{n}=4)$ and one each of $M$ gastri, $M$ gordonae, $M$ xenopi, $M$ terrae, and $M$ marinum by the pattern obtained on digestion of the 439 base pair fragment (data not shown). Results obtained using conventional methods of identification were consistent with these results.

In some cases multiplex PCR on members of the $M$ tuberculosis complex or $M$ avium yielded only the species specific product at 240 or 180 base pairs, respectively. Competitive inhibition of amplification of the larger 439 base pair product may have occurred. This does not create problems in identifying the mycobacterial species present.

\section{Discussion}

In recent years considerable advances have been made in the speed and ease of identification of the many mycobacterial species now implicated in disease. Species specific DNA probes have proved useful but are not available for the full range of mycobacterial pathogens. We have previously evaluated the method described by $\mathrm{Te}-$ lenti et $a l^{6}$ for identification of mycobacteria but found the requirement for digestion of all PCR products inconvenient. ${ }^{9}$ The multiplex PCR 
method described here permits rapid identification of most clinical isolates. Most of the remaining isolates can be identified by digestion of the 439 base pair fragment. Under ideal circumstances, the procedure can be performed in less than one working day and only small numbers of cells are required. Further evaluation of the method is needed to determine its potential for use in the clinical laboratory and how it might be incorporated into the workload of the clinical laboratory.

1 Wayne LG, Sramek HA. Agents of newly recognised or infrequently encountered mycobacterial diseases. Clin Microbiol Rev 1992;5:1-25.

2 Anargyros P, Astill DSJ, Lim ISL. Comparison of improved Bactec and Lowenstein-Jensen media for culture of mycobacteria from clinical specimens. $f$ Clin Microbiol 1990;28:1288-91.

3 Brisson-Noel A, Anzar C, Chureau C, Nguyen S, Pierre C, Bartoli M, et al. Diagnosis of tuberculosis by DNA amplification in clinical practice evaluation. Lancet 1991; 338:364-6.

4 Clarridge JE, Shawar JM, Shinnick TM, Plikaytis BB. Large scale use of polymerase chain reaction for detection of Mycobacterium tuberculosis in a routine mycobacteriology laboratory. $\mathcal{F}$ Clin Microbiol 1993;31:2049-56.
5 Peterson EM, Lu R, Floyd C, Nakasone A, Friedly G, de la Maza LM. Direct identification of Mycobacterium tuberculosis, Mycobacterium avium, and Mycobacterium intracellulare from amplified primary cultures in Bactec media using DNA probes. FClin Microbiol 1989;27:1543-7.

6 Telenti A, Marchesi F, Balz M, Bally F, Bottger EC, Bodmer $T$. Rapid identification of mycobacteria to the species level by polymerase chain reaction and restriction enzyme analysis. F Clin Microbiol 1993;31:175-8.

7 Vaneechoute M, DeBeenhouwer H, Claeys G, Verschraegen G, De Rouck A, Paepe N, et al. Identification of Mycobacterium species by using amplified ribosomal DNA bacterium species by using amplified ribosomal DN
restriction analysis. $f$ Clin Microbiol 1993;31:2061-5.

8 Plikaytis BB, Plikaytis BD, Yakrus MA, Butler WR, Woodley CL, Silcox VA, et al. Differentiation of slowly growing mycobacterium species, including Mycobacterium tuberculosis, by gene amplification and restriction fragment length polymorphism analysis. $\mathcal{f}$ Clin Microbiol 1992;30: 1815-22.

9 Cormican M, Glennon M, Ni Riain U, Flynn J. Evaluation of a PCR based method for identification of mycobacterial isolates. Ir $\mathcal{F} \mathrm{Med} S \mathrm{~S} i \mathrm{1995}$; in press.

10 Cormican M, Barry T, Gannon F, Flynn J. Use of polymerase chain reaction for early identification of Mycobacterium tuberculosis in positive cultures. 7 Clin Pathol 1992;45:601-4.

11 Shankar P, Manjunath N, Mohan KK, Prasad K, Behari M Shriniwas Aluja GK, et al. Rapid diagnosis of tuberculous meningitis by polymerase chain reaction. Lancet 1991; meningitis

12 Wilton $S$, Cousins D. Detection and identification of multiple mycobacterial pathogens by DNA amplification in a single tube. PCR Methods Appl 1992;1:269-73. 